See Article page 65

\section{Commentary: Biologic mustache for the modified Cabrol technique}

\author{
Jean Porterie, MD, \\ Dimitri Kalavrouziotis, MD, FRCSC, and \\ Siamak Mohammadi, MD, FRCSC
}

Prosthetic valve endocarditis (PVE) is a serious complication of valve replacement. In the aortic position, PVE carries a high risk of paravalvular abscess formation and total aortic root destruction. In such situations, redo surgery can be technically challenging, and may be associated with a high risk of recurrent prosthetic valve infection. Thus, consideration of an optimal surgical technique to avoid the risk of reinfection is essential. Guenther and colleagues ${ }^{1}$ report an interesting and elegant method of aortic root replacement for PVE complicated by extensive root abscess and poorly mobile coronary arteries. They perform a homograft aortic root replacement and reimplantation of the 2 coronary ostia by a modified Cabrol extension via a cryopreserved femoral artery. Concomitantly, the eroded aortomitral continuity is re-established with a bovine pericardial patch and the anterior mitral valve leaflet is resuspended.

Some specific aspects of their procedure deserve to be highlighted. Although the Cabrol technique was developed to handle situations in which mobilization of coronary buttons is unachievable without damage or increased tension, this approach may carry a risk of pseudoaneurysm formation and, more importantly, kinking of the coronary graft and occlusion. ${ }^{2}$ This risk may, theoretically, be even higher with the modified technique performed by Guenther and colleagues, ${ }^{1}$ due to the left-sided placement of the left coronary graft between the neoaorta and pulmonary artery, instead of a more direct route from the right side of the aorta as in the classic technique. Nevertheless, the specific situation of an

From the Department of Cardiac Surgery, Québec Heart and Lung Institute, Laval University, Québec City, Québec, Canada.

Disclosures: The authors reported no conflicts of interest.

The Journal policy requires editors and reviewers to disclose conflicts of interest and to decline handling or reviewing manuscripts for which they may have a conflict of interest. The editors and reviewers of this article have no conflicts of interest.

Received for publication Aug 22, 2020; revisions received Aug 22, 2020; accepted for publication Aug 26, 2020; available ahead of print Sept 14, 2020.

Address for reprints: Siamak Mohammadi, MD, FRCSC, Department of Cardiac Surgery, Québec Heart and Lung Institute, 2725 chemin Sainte-Foy, Québec City, Québec G1V 4G5 Canada (E-mail: siamak.mohammadi@fmed.ulaval.ca).

JTCVS Techniques 2020;4:68-9

2666-2507

Copyright $@ 2020$ The Authors. Published by Elsevier Inc. on behalf of The American Association for Thoracic Surgery. This is an open access article under the CC BY-NCND license (http://creativecommons.org/licenses/by-nc-nd/4.0/).

https://doi.org/10.1016/j.xjtc.2020.08.070
Check for updates

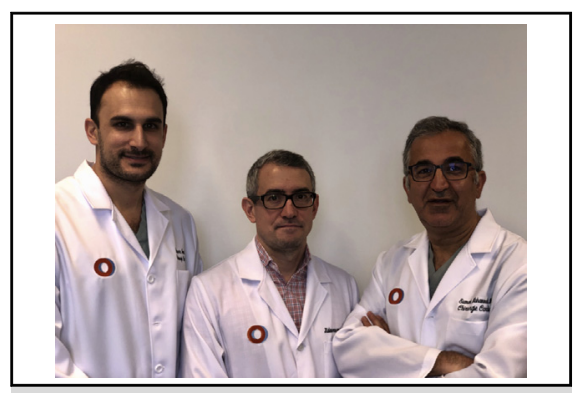

From left: Jean Porterie, MD, Dimitri Kalavrouziotis, MD, FRCSC, and Siamak Mohammadi, MD, FRCSC

CENTRAL MESSAGE

Redo surgery for prosthetic valve endocarditis can be technically challenging with a high risk of recurrent infection. Consideration of an optimal technique with biologic materials is essential.

aneurysmal native aorta seems to attenuate this risk, and has led the authors to adopt this modification with good results. The role of targeted cross-sectional imaging in the preoperative planning of these complex procedures is also emphasized. The authors highlight the relevance of homograft aortic root replacement as a valuable alternative to the use of prosthetic material in the setting of extensive tissue destruction in PVE, with very low rates of recurrent infection. ${ }^{3}$ However, homografts are not readily available at every institution, especially for urgent operations. In this setting, xenograft bioconduits are an excellent off-the-shelf alternative with very good outcomes. ${ }^{4}$ The authors remind readers that reoperation for PVE is among the more daunting operations that cardiac surgeons face, and that rigorous preoperative planning and the availability of multiple contingency strategies in a surgeon's armamentarium is essential, not only for a viable patient at the end of the surgery, but also for the prevention of future reinfection.

\section{References}

1. Guenther TM, Godoy L, Chen SA, Rodriguez VM. Homograft aortic root replacement with modified Cabrol extension using cryopreserved femoral artery for bioprosthetic aortic valve endocarditis. J Thorac Cardiovasc Surg Tech. 2020;4:65-7

2. Gelsomino S, Frassani R, Da Col P, Morocutti G, Masullo G, Spedicato L, et al. A long-term experience with the Cabrol root replacement technique for the management of ascending aortic aneurysms and dissections. Ann Thorac Surg. 2003;75: 126-31. 
3. Musci M, Weng Y, Hübler M, Amiri A, Pasic M, Kosky S, et al. Homograft aortic root replacement in native or prosthetic active infective endocarditis: twenty-year single-center experience. J Thorac Cardiovasc Surg. 2010;139:665-73.
4. Roubelakis A, Karangelis D, Sadeque S, Yanagawa B, Modi A, Barlow CW, et al. Initial experience with xenograft bioconduit for the treatment of complex prosthetic valve endocarditis. Perfusion. 2017;32:383-8. 